\title{
Design and synthesis of indole-substituted fullerene derivatives with different side groups for organic photovoltaic devices
}

\author{
Ning Wang ${ }^{\mathrm{a}}$, Xichang Bao ${ }^{\mathrm{a}}$, Chunpeng Yang ${ }^{\mathrm{a}}$, Jun Wang ${ }^{\mathrm{a}}$, Han Young Woo ${ }^{\mathrm{b}}$, Zhenggang Lan ${ }^{\mathrm{a}}$, \\ Weichao Chen ${ }^{\mathrm{a}}$, Renqiang Yang ${ }^{\mathrm{a}, *}$ \\ ${ }^{a}$ Qingdao Institute of Bioenergy and Bioprocess Technology, Chinese Academy of Sciences, 189 Songling Rd., Qingdao 266101, China \\ ${ }^{\mathrm{b}}$ Department of Nanofusion Technology, Department of Cogno-Mechatronics Engineering (WCU), Pusan National University, Miryang 627-706, Republic of Korea
}

\section{A R T I C L E I N F O}

\section{Article history:}

Received 1 November 2012

Received in revised form 3 December 2012

Accepted 11 December 2012

Available online 25 December 2012

\section{Keywords:}

Organic photovoltaic devices

Fullerene derivatives

Electron acceptors

Thin films

Indole

\begin{abstract}
A B S T R A C T
A series of indole-substituted fulleropyrrolidine derivatives with different side groups on a pyrrolidine rings, including methyl (OIMC60P), benzyl (OIBC60P), 2,5-difluoroinebenzyl (OIB2FC60P), and 2,3,4,5,6-pentafluoroinebenzyl (OIB5FC60P), have been synthesized and used as electron acceptor in the active layer of polymer-fullerene solar cells to investigate the effect of various substitute groups on the electronic structures, morphologies, and device performances. Optical absorption, electrochemical properties and solubility of the fullerene derivatives have been explored and compared. The inverted photovoltaic devices with the configuration ITO/ZnO/Poly(3-hexylthiophene)(P3HT):[60]fullerene derivatives $/ \mathrm{MoO}_{3} / \mathrm{Ag}$ have been prepared including the reference cell based on the P3HT: methyl $[6,6]$-phenyl-C61-butylate (PCBM) blend films. All the devices properties were measured in air without encapsulation. We also investigated the effect of the thermal annealing on the crystallinity and morphology of the active layer and the device performance. The device based on the blend film of P3HT and OIBC60P showed a power conversion efficiency of $2.46 \%$ under illumination by AM1.5G $\left(100 \mathrm{~mW} / \mathrm{cm}^{2}\right)$ after the annealing treatment at $120^{\circ} \mathrm{C}$ for $10 \mathrm{~min}$ in air.
\end{abstract}

(c) 2012 Elsevier B.V. All rights reserved.

\section{Introduction}

Organic photovoltaic devices (OPVs), which are expected to have great advantages such as flexibility, lightweight, and low cost of large-volume manufacturing, give a bright future of large scale production and application of the clean and renewable solar energy [1,2]. Recently, OPVs based on conjugated organic materials and fullerene derivatives have shown a remarkable breakthrough, the power conversion efficiency (PCE) has exceeded 8\% [3-5]. The active layer of the OPVs is a blend film composed of electron-donor materials (conjugated polymers or small molecules) and acceptor materials (fullerene derivatives, etc.) with the bulk heterojunction structure [6]. During the past decades, in order to improve the PCE of the OPVs,

\footnotetext{
* Corresponding author. Fax: +86 53280662778.

E-mail address: yangrq@qibebt.ac.cn (R. Yang).
}

many research efforts have been devoted to develop novel electron-donors materials with good solubility, low band gap, optimized energy levels, broad absorption, and high mobility [7-14]. However, less attention has been paid to the electron acceptors. Only recently, various fullerene derivatives have been developed, which play as acceptors in the active layer of OPVs $[15,16]$. In our knowledge, $[6,6]-$ phenyl-C61-butylate methyl ester (PCBM) is one of the most widely used acceptor materials due to its advantage of good solubility in common organic solvents, high electron mobility and affinity [17-21], whereas, PCBM suffers from some well-known drawbacks, such as weak absorption in visible region, rather low energy level of lowest unoccupied molecular orbital (LUMO) and instability of three-membered ring group [16]. To optimize the structure and properties of the fullerene derivatives, two kinds of strategies have been tried to modify the chemical structure of $n$-type fullerene derivatives. One way is to go beyond 
PCBM and construct other fullerene derivatives such as indene substituted fullerene derivatives [22], fulleropyrrolidine derivatives $[23,24]$, indolinone-substituted methanofullerene [25], and di(4-methyl-phenyl)methanofullerene bis-adduct [26]. The other strategy is to optimize the substitute groups such as changing aromatic units or alkyl chain length [27-29]. For example, the modification of the side group of PCBM significantly affects its solubility and morphology in poly(3-hexylthiophene)(P3HT)/fullerene derivatives blend films, which leads to various photovoltaic performance of organic solar cells [30,31]. Another work is reported by Kim's group. They showed that the different performance of the photovoltaic devices based on P3HT and o-xyleneyl C60 bis-adduct derivatives were largely caused by changing the side groups of the fullerene derivatives [27].

The exploration of new fullerene derivatives and the investigation of their structure-property relationships should play a key role to improve the performance of OPVs [15]. Herein we synthesized a series of indole-substituted fulleropyrrolidine derivatives. The introduction of indolebased groups in principle should improve light harvesting ability of the acceptors due to more aromatic groups [25]. The fulleropyrrolidine derivatives can easily be synthesized via Prato reaction [32]. The five-member ring structures provide some advantages for OPVs applications, such as high electron affinity, excellent stability and good charge transport ability [33-35]. The pyrrolidine rings were selectively substituted with methyl (OIMC60P), benzyl (OIBC60P), 2,5-difluorobenzyl (OIB2FC60P), and 2,3,4,5,6-pentafluorine-benzyl (OIB5FC60P). The inclusion of such side groups significantly change the solubility of fullerene derivatives, influence the phase-separation morphology of blend films containing the fullerene acceptors and P3HT donor polymers, and thus result in different PCEs ranging from 0.34 to $2.46 \%$. The effect of the thermal annealing on the crystallinity and morphology of the active layer was also been explored and analyzed by X-ray diffraction (XRD) and atomic force microscopy (AFM).

\section{Experiments}

\subsection{Materials}

All reagents were bought from commercial sources and were used without further purification. The solvents were purified with standard methods. Silica gel (200-300 mesh) was used for column chromatography. New products were characterized by ${ }^{1} \mathrm{H}$ NMR, ${ }^{13} \mathrm{C}$ NMR, and Atmospheric Pressure Chemical Ionization-Time of Flight (APCI-TOF) high resolution mass spectra (HRMS).

\subsection{Measurements}

${ }^{1} \mathrm{H}$ NMR and ${ }^{13} \mathrm{C}$ NMR spectra were recorded on a Bruker DRX-600 spectrometer. APCI-TOF HRMS were performed on Bruker Maxis UHR-TOF (both positive and negative ion reflector mode).

The ultraviolet-visible (UV-Vis) spectra were measured on a Varian Cary 50 spectrophotometer. The blend films were prepared on quartz by spinning coating the mixture solution of P3HT and fullerene derivatives with a weight ratio of $1: 1$ in chlorobenzene $(15 \mathrm{mg} / \mathrm{mL})$, respectively.

The crystallization of the active layer was analyzed using XRD (Mac Science, $\mathrm{Cu} \mathrm{K} \alpha$ wavelength of $0.154056 \mathrm{~nm}$ ), and the films for XRD were formed on silicon slides by spinning coating the same mixture solution of P3HT and fullerene derivatives for UV measurements.

The electrochemical behaviors of the fullerene derivatives were investigated by cyclic voltammograms (CV). The CV was performed in a solution of tetrabutylammonium hexafluorophosphate $\left(\mathrm{Bu}_{4} \mathrm{NPF}_{6}\right)(0.04 \mathrm{M})$ in o-dichlorobenzene. A three-electrode cell consisting of a glassy carbon working electrode, a Pt counter electrode and an $\mathrm{Ag} / \mathrm{AgCl}$ reference electrode was used. The scan rate was $100 \mathrm{mV} / \mathrm{s}$. The potential of ferrocene/ferrocenium $\left(\mathrm{Fc} / \mathrm{Fc}^{+}\right)$ was measured to be $0.58 \mathrm{~V}$ compared to the $\mathrm{Ag} / \mathrm{AgCl}$ electrode under the same conditions. It is assumed that the redox potential of $\mathrm{Fc} / \mathrm{Fc}^{+}$, has an absolute energy level of $-4.8 \mathrm{eV}$ to vacuum.

AFM images were obtained on an Agilent 5400 scanning probe microscope using AC mode. The blend films of P3HT and fullerene derivatives were prepared under the same experimental conditions as that of optimized photovoltaic devices fabrication.

Density functional theory (DFT) calculations were performed using the Gaussian 09 package with the nonlocal hybrid Becke three-parameter Lee-Yang-Parr (B3LYP) function and the $6-31 \mathrm{G}^{*}$ basis set to obtain the HOMO and LUMO levels after optimizing the geometry of materials using the same method.

\subsection{Fabrication of photovoltaic devices}

The inverted photovoltaic devices were fabricated and characterized in air without encapsulation. All cells were fabricated on ITO coated glass substrates with a nominal sheet resistance of $15 \Omega /$ sq. The substrates were cleaned in an ultrasonic bath with detergent, ultra pure water, acetone, and isopropyl alcohol for $20 \mathrm{~min}$, and then dried in a laboratory oven at $80^{\circ} \mathrm{C}$ for one night. The $\mathrm{ZnO}$ solution was prepared using zinc acetate and the equally molar monoethanolamine dissolved in 2-methoxyethanol, and then the mixture was stirred vigorously at $60^{\circ} \mathrm{C}$ to yield a homogeneous transparent solution. The ITO surfaces were coated by the above $\mathrm{ZnO}$ solutions with spin-coated speeds at $2000 \mathrm{rmp}$ for $40 \mathrm{~s}$, and then, treated in an oven at $100{ }^{\circ} \mathrm{C}$ for $16 \mathrm{~h}$. A blend solution of poly(3-hexylthiophene) (P3HT) (Lumtec Inc.) and PCBM (American Dye Sources Inc.) or our fullerene derivatives with a weight ratio of $1: 1$ in chlorobenzene $(15 \mathrm{mg} / \mathrm{mL})$ under argon atmosphere was stirred for $4 \mathrm{~h}$, respectively, and then spin-coated on $\mathrm{ZnO}$-coated ITO substrate to form the active layer $(100 \mathrm{~nm})$ in air. Subsequently, $\mathrm{MoO}_{3}(3 \mathrm{~nm})$ and $\mathrm{Ag}$ $(80 \mathrm{~nm})$ were thermal evaporated with VPC-1100 under $2.0 \times 10^{-5} \mathrm{~Pa}$, followed by post-annealing at $120^{\circ} \mathrm{C}$ for $10 \mathrm{~min}$ still in atmosphere. The cell's active area was $0.1 \mathrm{~cm}^{2}$. The film thickness was measured with a Veeco Dektak 150 surface profiler. The current density-voltage $(\mathrm{J}-\mathrm{V})$ characteristics were recorded with a Keithley 2420 source measurement unit under simulated $100 \mathrm{~mW} / \mathrm{cm}^{2}$ 
(AM1.5G) irradiation from a Newport solar simulator. Light intensity was calibrated with a standard silicon solar cell. The external quantum efficiencies (EQE) of solar cells were analyzed using a certified Newport incident photon conversion efficiency (IPCE) measurement system.

\section{Results and discussion}

\subsection{Synthesis}

As shown in Scheme 1, indole-3-carboxaldehyde was alkylated by 1 -bromooctane to afford 1-octylindole-3-carboxaldehyde in the presence of tetrabutylammonium bromide (TBAB) and sodium hydroxide [36]. [60]Fulleropyrrolidine derivative OIHC60P was synthesized from glycine and 1-octylindole-3-carboxaldehyde based on the 1,3-dipolar cycloaddition [32] of azomethine ylide to $\mathrm{C} 60$ in refluxed chlorobenzene for $5 \mathrm{~h}$. We optimized the reaction time in order to avoid the formation of multi-addition adducts, which led to a relative low yield (about 24\%) of the desired mono-addition adduct OIHC60P. As recompense, this made it easier to purify the desired product by silica-gel column chromatography. The unreacted $\mathrm{C} 60$ (about $50 \%$ of the total amount) could be recycled. The compound OIHC60P reacted with corresponding aldehydes respectively to give $\mathrm{N}$-alkylated derivatives at the aid of sodium triacetoxyborohydride and acetic acid in very high yields from $90 \%$ to $96 \%$ [37]. The products were characterized by ${ }^{1} \mathrm{H}$ NMR, ${ }^{13} \mathrm{C}$ NMR and HRMS.

The solubility of fullerene derivatives in chlorobenzene, which is a typical solvent for fabrication of P3HT-fullerene derivatives solar cells, is an important character of acceptor materials used in the active layer of photovoltaic device. The optimal solubility is reported to be in the range of $30-80 \mathrm{mg}$ at room temperature [38]. The compound OIBC60P, OIB2FC60P, OIB5FC60P exhibited excellent solubility in chlorobenzene at room temperature, which were evaluated to be $42 \mathrm{mg} \mathrm{mL}^{-1}, 40 \mathrm{mg} \mathrm{mL}^{-1}$ and $39 \mathrm{mg} \mathrm{mL}^{-1}$, respectively. However, the compound OIHC60P and OIMC60P showed lower solubility, which were measured to be $28 \mathrm{mg} \mathrm{mL}^{-1}$ and $24 \mathrm{mg} \mathrm{mL}^{-1}$ in chlorobenzene at room temperature, respectively. This result indicates that the inclusion of benzyl group on fulleropyrrolidine can improve the solubility of the fullerene derivatives. The difference of the solubility of the fullerene derivatives is expected to have great influence on the morphology and performance of devices.

\subsection{Optical properties}

UV-Vis absorption spectra of the fullerene derivatives in dichloromethane $\left(\mathrm{CH}_{2} \mathrm{Cl}_{2}\right)$ with the concentration of $2 \times 10^{-5} \mathrm{~mol} / \mathrm{L}$ are shown in Fig. 1 . The absorption band

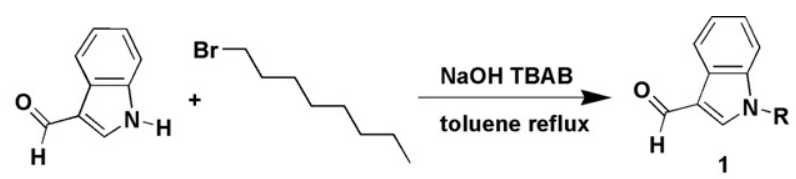<smiles>[R]n1cc(C(=O)C[NH2+][CH2])c2ccccc21</smiles>
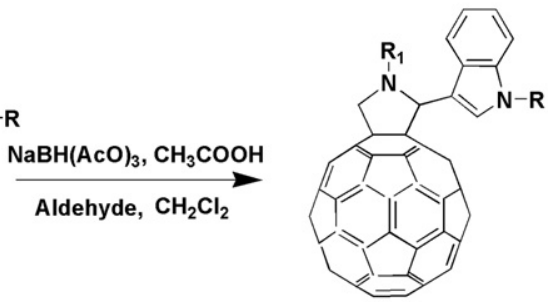

OIHC60

OIBC60P

$\mathbf{R}_{1}=\mathbf{H}$

$\mathbf{R}_{1}=-\xi \mathrm{CH}_{3}$

$\mathbf{R}_{1}=$<smiles>Cc1ccccc1</smiles>

OIB2FC60P

OIB5FC60P

\section{$\mathbf{R}_{\mathbf{1}}$}<smiles>N#Cc1ccc(F)cc1F</smiles>

$\mathbf{R}_{\mathbf{1}}$<smiles>CC(C)(C)Cc1c(F)c(F)c(F)c(F)c1F</smiles>

$\mathrm{R}=\mathrm{C}_{8} \mathrm{H}_{17}$

$\mathrm{R}=\mathrm{C}_{8} \mathrm{H}_{17}$

$\mathrm{R}=\mathrm{C}_{8} \mathrm{H}_{17}$

$\mathrm{R}=\mathrm{C}_{8} \mathrm{H}_{17}$

$\mathrm{R}=\mathrm{C}_{8} \mathrm{H}_{1}$

Scheme 1. Synthetic route for fullerene derivatives. 


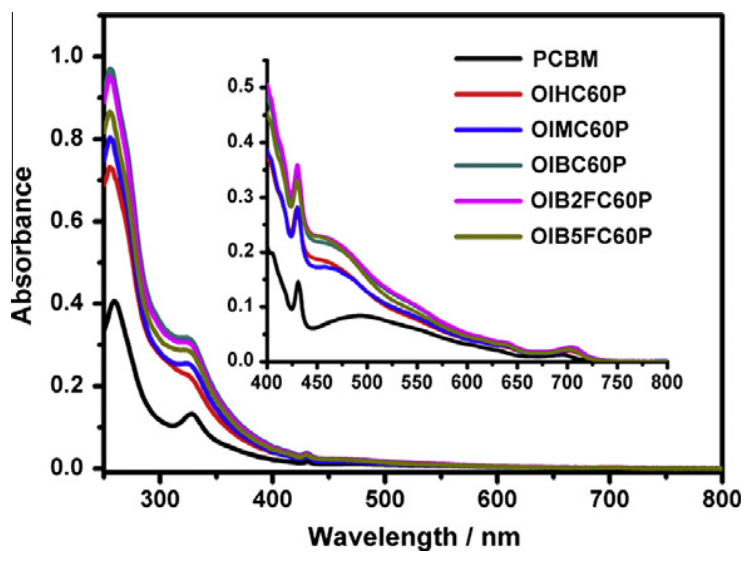

Fig. 1. Absorption spectra of $\mathrm{PCBM}$ and fullerene derivatives in $\mathrm{CH}_{2} \mathrm{Cl}_{2}$ $\left(2 \times 10^{-5} \mathrm{M}\right.$, the cell thickness $\left.\mathrm{d}=1 \mathrm{~mm}\right)$. Inset shows the absorption spectra at $400-800 \mathrm{~nm}(\mathrm{~d}=1 \mathrm{~cm})$.

centered in the range of $300-700 \mathrm{~nm}$ is essentially similar for each derivative. The sharp peak at ca. $430 \mathrm{~nm}$ and the weak peak at ca. $700 \mathrm{~nm}$, which were attributed to the absorption of $\mathrm{C} 60$, were consistent with the literature [39]. It should be mentioned that the absorbance of indole-substituted fullenene derivatives were much stronger than that of PCBM in the visible region, which could be due to the contribution of the indole functional groups. As shown in Fig. S1 and Table 2, the optical band gap of PCBM is $1.73 \mathrm{eV}$, which was comparable to the other reports [24].
Under the same experiment conditions, the indole-substituted fulleropyrrolidine derivatives showed as similar optical bands as that of PCBM, the data was summarized in Table 2. Furthermore, the addition of different substitute group on pyrrolidine ring did not induce significant changes of the energy band gap, which was due to the conjugation-interrupted linkage of the substitute group on fulleropyrrolidine ring [29].

Fig. 2 shows the UV-Vis absorption spectra of P3HT and fullerene derivatives (1:1 by weight) blend films before and after annealing at $120^{\circ} \mathrm{C}$ for $10 \mathrm{~min}$. The thickness of the blend films is $100 \mathrm{~nm}$. The absorption intensity at ca. $330 \mathrm{~nm}$ was quite different in the blend films, which was probably due to the various substitute groups on the fullerene derivatives and different miscibility with P3HT. As shown in Fig. 2a, the spectra of as-cast films based on P3HT and PCBM showed only one broad peak at $476 \mathrm{~nm}$, while the peaks at 504, $545 \mathrm{~nm}$ and $596 \mathrm{~nm}$ (Fig. 2b) appeared after the film was annealed. The red-shifted absorption peaks of P3HT were attributed to the stronger chain packing of P3HT which resulted from stronger inter chain interactions after the blend film of P3HT and PCBM was annealed [40]. In the cases of OIBC60P, OIB2FC60P, the similar spectra changes were observed after the blend films were annealed. Interestingly, the non-annealed blend films of P3HT and OIHC60P showed a broad peak at $514 \mathrm{~nm}$ with two shoulder peaks at $553 \mathrm{~nm}$ and $604 \mathrm{~nm}$, consistent with characteristic peaks of annealed film of P3HT [41]. Furthermore, there were no significant changes of peak position after the film was annealed at $120^{\circ} \mathrm{C}$ (Fig. 2b). This result

Table 1

XRD data summary.

\begin{tabular}{|c|c|c|c|c|c|c|c|}
\hline Experimental values & РCBM & OIHC60P & OIMC60P & OIBC60P & OIB2FC60P & OIB5FC60P & \\
\hline \multirow[t]{2}{*}{$\beta^{\mathrm{a}}($ radian $)$} & Before annealing & 0.0072 & 0.0082 & 0.0084 & 0.0089 & 0.0087 & 0.0072 \\
\hline & After annealing & 0.0052 & 0.0059 & 0.0059 & 0.0058 & 0.0066 & 0.0052 \\
\hline \multirow[t]{2}{*}{$2 \theta$} & Before annealing & 5.51 & 5.45 & 5.47 & 5.59 & 5.63 & 5.47 \\
\hline & After annealing & 5.38 & 5.39 & 5.39 & 5.49 & 5.47 & 5.37 \\
\hline \multirow[t]{2}{*}{$\tau^{\mathrm{b}}(\mathrm{nm})$} & Before annealing & 19.2 & 16.7 & 16.4 & 15.4 & 15.7 & 19.1 \\
\hline & After annealing & 26.2 & 23.1 & 23.1 & 23.8 & 20.7 & 26.2 \\
\hline \multirow[t]{2}{*}{$h^{\mathrm{c}}$} & Before annealing & 138 & 628 & 406 & 147 & 242 & 431 \\
\hline & After annealing & 1253 & 1134 & 635 & 548 & 639 & 562 \\
\hline$\Delta h=h_{\text {after }} / h_{\text {before }}{ }^{\mathrm{d}}$ & & 9.1 & 1.8 & 1.6 & 3.7 & 2.6 & 1.3 \\
\hline
\end{tabular}

a The units were converted to radian.

b The values were calculated from Scherrer equation.

c The values represented the diffraction intensity of the blend films.

d The values represented the change of the diffraction intensity after and before the blend films were annealed.

Table 2

Energy levels obtained from experimental and theoretical methods.

\begin{tabular}{|c|c|c|c|c|c|c|}
\hline & \multicolumn{3}{|c|}{ Experimental values $^{\mathrm{a}}$} & \multicolumn{3}{|c|}{ Theoretical values $^{\mathrm{b}}$} \\
\hline & HOMO (eV) & LUMO (eV) & $\mathrm{Eg}^{\text {opt }}(\mathrm{eV})$ & HOMO (eV) & LUMO (eV) & $\mathrm{Eg}(\mathrm{eV})$ \\
\hline PCBM & -5.438 & -3.709 & 1.729 & -5.883 & -3.356 & 2.527 \\
\hline OIHC60P & -5.379 & -3.671 & 1.708 & -5.653 & -3.252 & 2.401 \\
\hline OIMC60P & -5.384 & -3.678 & 1.706 & -5.590 & -3.245 & 2.345 \\
\hline ОІВС60Р & -5.354 & -3.650 & 1.704 & -5.614 & -3.231 & 2.383 \\
\hline OIB2FC60P & -5.389 & -3.686 & 1.703 & -5.563 & -3.255 & 2.308 \\
\hline OIB5FC60P & -5.448 & -3.737 & 1.711 & -5.654 & -3.300 & 2.354 \\
\hline
\end{tabular}

${ }^{a}$ LUMO values were determined by CV results, while HOMO values were estimated by subtracting from optical gap (Eg).

b All chemical structures were optimized with the B3LYP function and DEF2-SVP. 

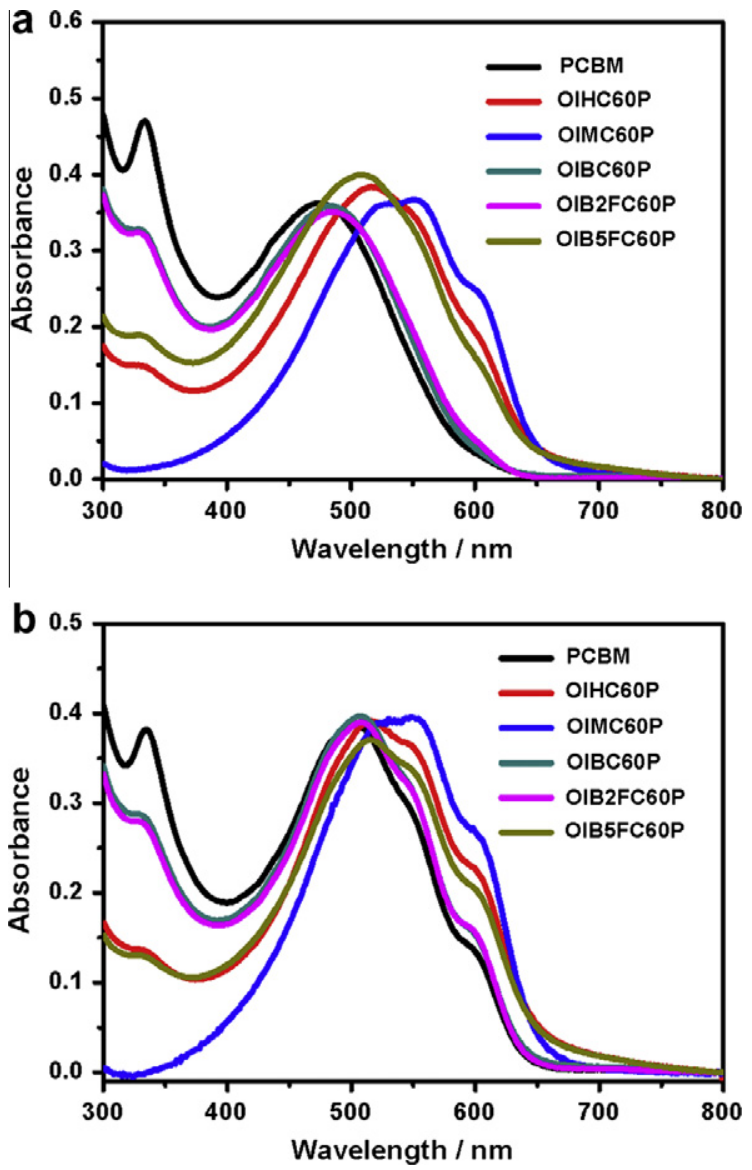

Fig. 2. Absorption spectra of blend films of P3HT and fullerene derivatives ( $1: 1$ by weight) before (a) and after (b) annealing at $120^{\circ} \mathrm{C}$ for $10 \mathrm{~min}$.

indicated that the P3HT tend to crystallize when mixing with OIHC60P without annealing. The same phenomena were found in the cases of OIMC60P and OIB5FC60P. Thus fullerene derivatives OIHC60P, OIMC60P and OIB5FC60P could induce the crystallization of P3HT and their red shift of the absorption spectra will improve the light harvesting ability of the blend films.

\subsection{XRD spectra}

To further investigate the crystallization changes of P3HT/fullerene derivatives blend films with and without annealing, we performed XRD characterization. As we all know, the size of the crystal domains could be calculated according to the Scherrer equation [42]:

$\tau=\frac{K \lambda}{\beta \cos \theta}$

where $K$ is the shape factor (0.89), $\lambda$ is the X-ray wavelength $(0.154056 \mathrm{~nm}), \beta$ is the line broadening at full width at the half maximum intensity (FWHM) in radians, $\theta$ is the Bragg angle, and $\tau$ is the mean size of the ordered domains. The crystallinity degree of the blend films could be reflected by the intensity of the diffraction peaks $(h)$. To com-
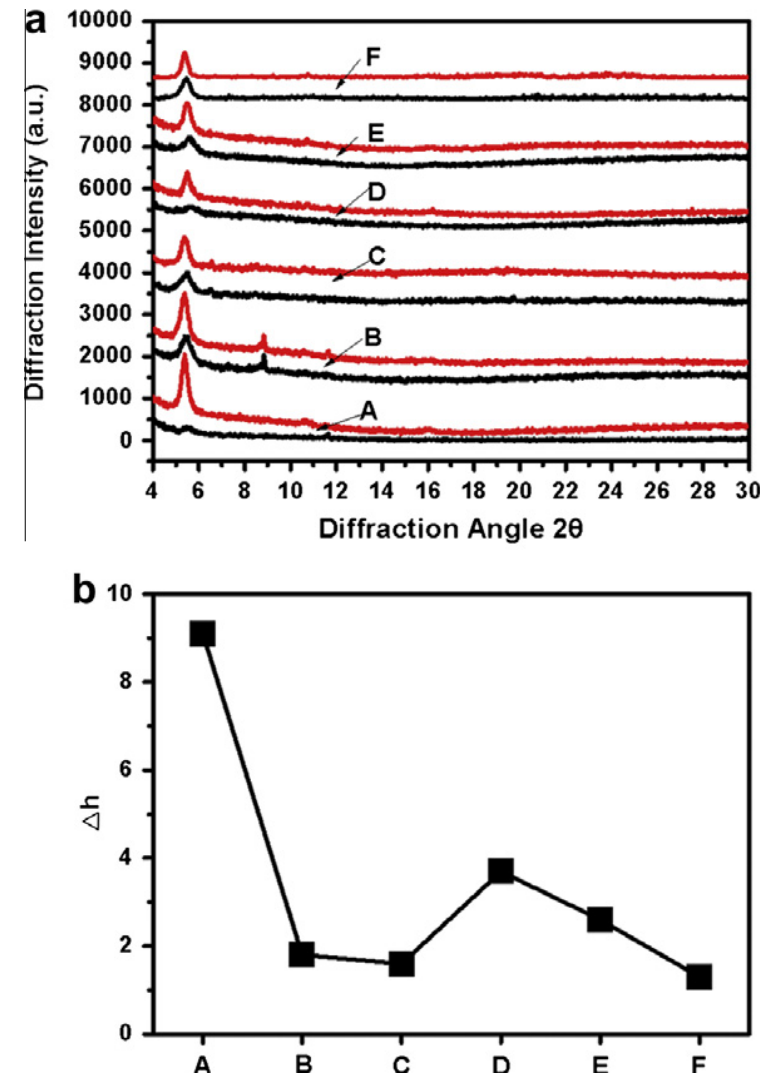

Fig. 3. (a) XRD spectra of the blend films of $\mathrm{P} 3 \mathrm{HT}$ and fullerene derivatives before (black line) and after (red line) thermal annealing. (b) The diffraction intensity changing trend of the blend films with and without annealing, where $\Delta h$ represents the ratio of diffraction intensity after and before annealing. A-F represents PCBM, OIHC60P, OIMC60P, OIBC60P, OIB2FC60P, and OIB5FC60P, respectively. (For interpretation of the references to colour in this figure legend, the reader is referred to the web version of this article.)

pare the influence of annealing on the crystallinity of the blend films, we define the $\Delta h$ value as the ratio of the diffraction peak intensity after and before annealing treatment.

As shown in Fig. 3a, all the non-annealed blend films of P3HT and fullerene derivatives exhibited the (100)-P3HT diffraction peaks at ca. $5.5^{\circ}$, which meant the existence of the crystal regions of P3HT in all the blend films [43]. The $2 \theta$ angles of the maximum diffraction peak of the ascast films were all greater than those of annealing films, which indicated that the mean interlayer spacing for the as-cast blend films was less than that of the annealing ones [44]. As shown in Table 1, the FWHM $(\beta)$ of the blend films were decreased after the films were annealed, which indicated that the mean size of the ordered domains $(\tau)$ in the blend films were increased according to the Scherrer equation. All the diffraction intensities of (100)-P3HT peak were increased after the films annealed, however, the changing trends were quite different. In the case of blend films based on P3HT and PCBM, a weak and broad (100)-P3HT peak was observed before the film was annealed, the peak intensity significantly increased by 9.1 times (the $\Delta h$ value in Table 1) after the film was annealed. The similar changing 


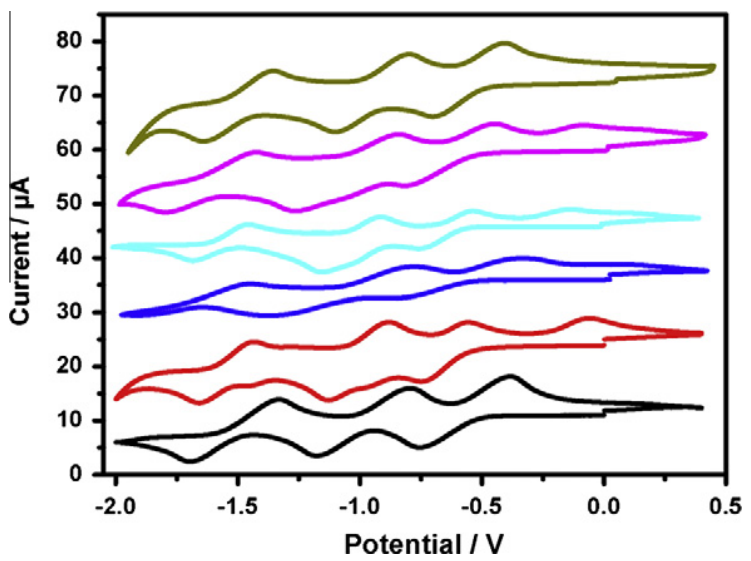

Fig. 4. Cyclic voltammograms of PCBM, OІHC60P, ОIMC60P, ОIBC60P, OIB2FC60P, OIB5FC60P (from bottom to top) in diclorobenzene containing $0.04 \mathrm{M} \mathrm{Bu}_{4} \mathrm{NPF}_{6}\left(\right.$ scan rate $\left.=100 \mathrm{mV} \mathrm{s}^{-1}\right)$.

trend was found in the cases of OIBC60P and OIB2FC60P with $\Delta h$ values as 3.7 and 2.6 , respectively. The results indicated that OIBC60P and OIB2FC60P had good miscibility with P3HT in the non-annealed blend films, and the crystallinity of the films increased greatly after annealing treatment $[45,46]$. However, the situation was quite different in the case of OIHC60P, a stronger (100)-P3HT peak was observed before the blend film was annealed compared to that of PCBM in the same condition, which indicated that the crystallinity in the blend film of P3HT and OIHC60P was stronger [47]. The peak intensity was further increased only by 1.8 times after the film was annealed which was much less than those of PCBM, OIBC60P, and OIB2FC60P. Furthermore, a peak at $8.82^{\circ}$ was found which was assigned to the crystallization peak of fullerene derivative OIHC60P $[44,48]$. The XRD results of P3HT/ OIHC60P blend films indicated that OIHC60P was easy to self aggregation and then induced the crystallization of the P3HT in the as-cast films. The similar result was found in the cases of OIMC60P and OIB5FC60P except that no crystallization peak of fullerene derivatives were found, which meant the self aggregation of OIMC60P and
OIB5FC60P was not as strong as that of OIHC60P. The changing trend of the diffraction intensity of the blend films before and after annealing was summarized in Fig. $3 \mathrm{~b}$ and Table 1 . The $\Delta h$ value decreased in the order OIBC60P $(\Delta h=3.7), \quad$ OIB2FC60P $(\Delta h=2.6), \quad$ OIHC60P $(\Delta h=1.8)$, OIMC60P $(\Delta h=1.6)$, and OIB5FC60P $(\Delta h=1.3)$. The XRD experiment result was consistent well with the conclusion which we deduced from the absorption spectra. The fullerene derivatives OIHC60P, OIMC60P and OIB5FC60P which had low $\Delta h$ values can easily induce the crystallization of P3HT in the as-cast blend film. On the contrary, OIBC60P, OIB2FC60P could form a relatively homogeneous blend films with P3HT, and the crystallization of the P3HT would be increased greatly when the blend films were annealed.

\subsection{Electrochemical characteristics}

The CV spectra of PCBM and fulleropyrrolidine derivatives have been measured (Fig. 4). The obtained values of the HOMO, LUMO and optical gap are summarized in Table 2, which also contains theoretical results from the DFT calculations for comparison. The $\mathrm{CV}$ spectrum of PCBM showed three reversible waves in the negative region peaked at $-0.756,-1.179$, and $-1.696 \mathrm{~V}$ versus $\mathrm{Ag} / \mathrm{AgCl}$, which reflected the formation of monoanion, dianion and trianion of fullerene moiety. The onset of the first reduction wave was located at $-0.514 \mathrm{~V}$, indicating that the LUMO level of PCBM is $-3.709 \mathrm{eV}$. The LUMO level of the fullerenepyrrolidine derivative OIHC60P was $38 \mathrm{mV}$ higher than that of the PCBM and was comparable with that of OIMC60P. In the case of OIBC60P, the inclusion of benzyl group makes the LUMO level raised to $-3.650 \mathrm{eV}$. The LUMO levels of OIB2FC60P and OIB5FC60P were $36 \mathrm{eV}$ and $87 \mathrm{eV}$ lower compared to that of OIBC60P, respectively, which was due to the electron withdraw property of fluorine atoms. It can be seen that the energy band-gaps and LUMO energy levels did not change much due to the conjugation interrupted linkage of the side groups on fulleropyrrolidine. Fig. 5 shows the DFT calculation structures of the compounds. One can see that the LUMO levels of the
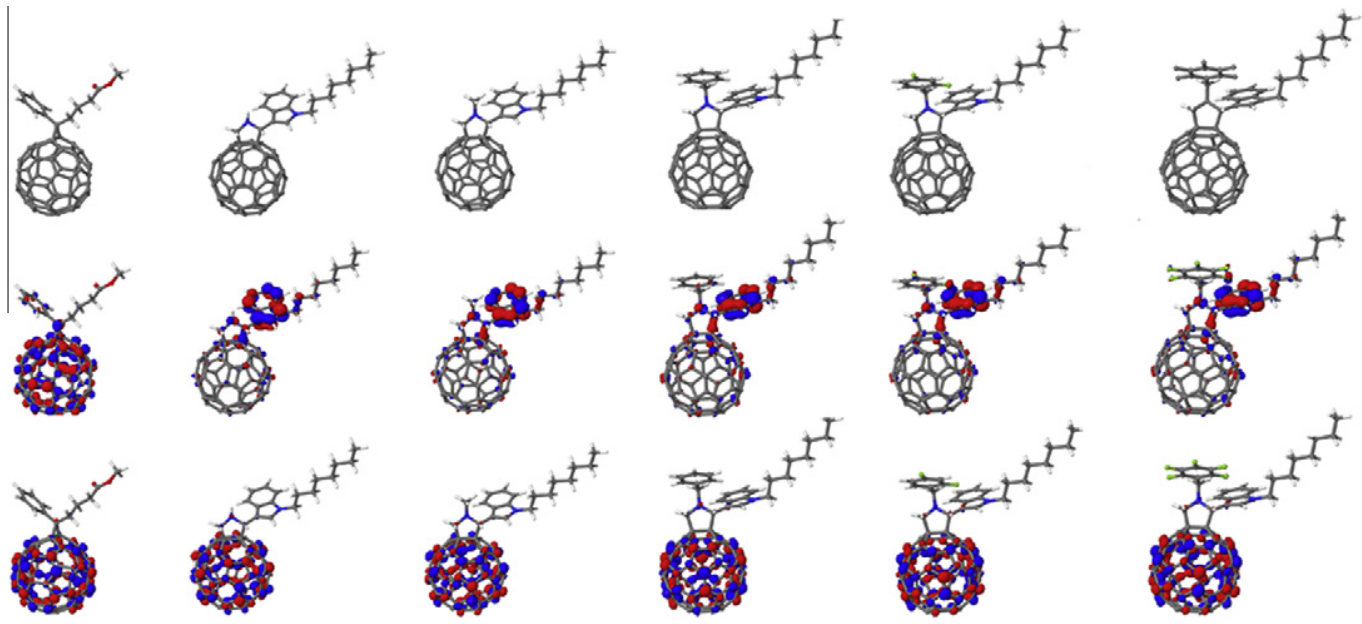

Fig. 5. The DFT calculations of PCBM, OIHC60P, OIMC60P, OIBC60P, OIB2FC60P, OIB5FC60P (from left to right). 
fullerene derivatives mainly locate on the C60, and the HOMO mainly on the indole units. This phenomenon was consistent with the reported results [49,50]. The theoretical energy level values are summarized in Table 2 . The calculation results indicated that electronic structures of the fullerene derivatives did not change remarkably, which was consistent with the experimental values.
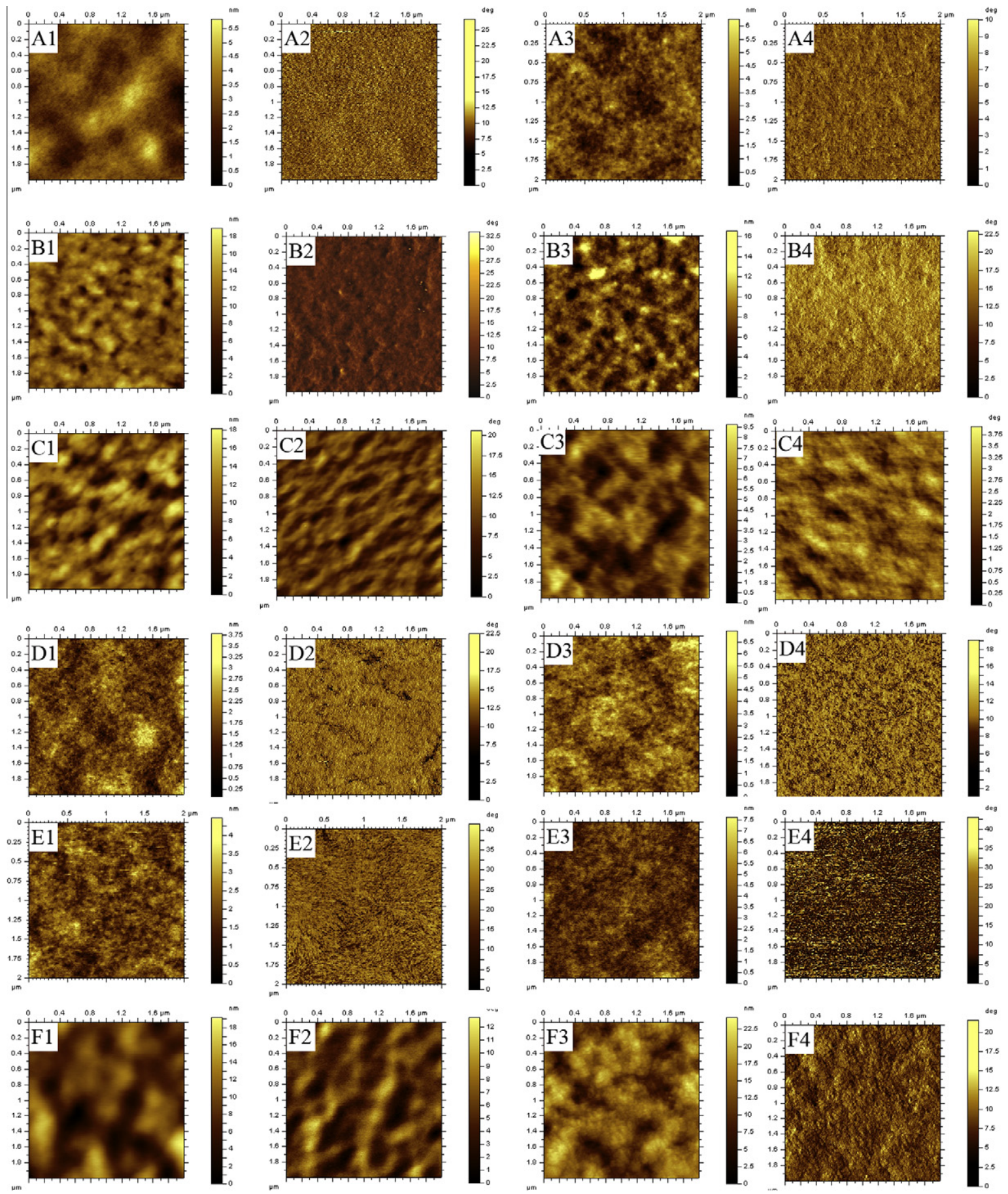

Fig. 6. AFM topographic and phase images of the blend films of P3HT and fullerene derivatives PCBM (A1-A4), OIHC60P (B1-B4), OIMC60P (C1-C4), OIBC60P (D1-D4), OIB2FC60P (E1-E4), OIB5FC60P (F1-F4), before (left two column) and after (right two column) thermal annealed. 
those used for the optimized photovoltaic devices. Obviously different morphologies appear upon the variation of the substitute groups in the fullerene derivatives. As shown in Fig. 6D1 and E1, the as-cast P3HT blend films containing OIBC60P, OIB2FC60P formed relatively homogeneous better-mixed morphologies, with the roommean-square (RMS) roughness of 0.41 and $0.52 \mathrm{~nm}$, respectively, which were similar to that of the P3HT/PCBM blend films (Fig. 6A1). More crystallized ordered domains were found after the blend films were annealed (Fig. 6D3 and E3). Fig. 6D4 and E4 showed that interpenetrating phase separations were formed which could induce the excellent exciton dissociation and gathering channels of charge carries. In contrast, OIHC60P, OIMC60P and OIB5FC60P showed relatively large aggregation domains with the size of over $100 \mathrm{~nm}$. The rough surfaces were very obvious before the annealing treatment with the RMS roughness of $2.27 \mathrm{~nm}, 2.66 \mathrm{~nm}$, and $3.00 \mathrm{~nm}$, respectively. This result correlated well with the absorption and XRD spectra of the as-cast blend films. The poor miscibility of OIHC60P and OIMC60P with P3HT was due to the low solubility of the two fullerene derivatives. However, the situation of OIB5FC60P, which had good solubility in chlorobenzene, was quite different. It was assumed that the five fluorine atoms substituted on the benzyl group of OIB5FC60P induced the strong trend of the self aggregation of the fullerene derivative.

\subsection{Photovoltaic properties}

Inverted photovoltaic devices, which have the advantage of stability in air, have recently attracted high interest [42]. To investigate the relationship between the chemical structures of the fullerene derivatives and photovoltaic properties, we used OIHC60P, OIMC60P, OIBC60P, OIB2FC60P, and OIB5FC60P as acceptors to fabricate inverted photovoltaic devices (ITO/ZnO/P3HT: fullerene derivatives $/ \mathrm{MoO}_{3} / \mathrm{Ag}$ ). Their performances before and after annealing treatment were measured under the illumination of AM1.5G $100 \mathrm{~mW} / \mathrm{cm}^{2}$. The characteristics of the photovoltaic devices are shown in Figs. 7 and 8, and sum- marized in Table 3. Under our experiment conditions, the P3HT:PCBM devices exhibited the PCE of $2.85 \%$, with open circuit voltage (Voc) of $0.61 \mathrm{~V}$, short circuit current (Jsc) of $8.12 \mathrm{~mA} / \mathrm{cm}^{2}$ and fill factor (FF) of $57 \%$. It was reasonable for the inverted devices P3HT/PCBM which were annealed at $120{ }^{\circ} \mathrm{C}$ for $10 \mathrm{~min}$ in air without encapsulation. As shown in Table 3, under the same annealing treatment conditions, the P3HT: fulleropyrrolidine derivatives devices showed remarkably varying PCE values from 0.35 (OIMC60P) to $2.46 \%$ (OIBC60P). This indicated that the modification of side groups has remarkable impact on the photovoltaic performance of fullerene derivatives. It should be noted that the Jsc of OIB2FC60P-based devices was $0.58 \mathrm{~mA} / \mathrm{cm}^{2}$ higher than that of OIBC60P, and it was confirmed by the external quantum efficiencies (EQEs) results (Fig. S2). The difference in the morphologies is presumably one of the main reasons for the enhancement of Jsc (Fig. 8D4 and E4) [51]. However, when the side group was changed to 2,3,4,5,6-pentafluorobenzyl moiety, the performance of the P3HT/OIB5FC60P devices dropped greatly, which was due to the presence of the large domain and the heterogeneous phases (see Fig. 6). The devices based on OIHC60P and OIMC60P with limited solubility and low miscibility with P3HT resulted in poor devices performance. The device performance before and after annealing treatment were investigated and compared each other. As shown in Fig. 8, in the cases of OIBC60P and OIB2FC60P which had good nano-scale interpenetrating morphologies of the active films, the Voc were stable after annealing treatment, however, the Jsc, FF, and PCE greatly increased after annealing in air. On the contrary, in the cases of OIHC60P, OIMC60P which had low solubility in chlorobenzene, the Voc, Jsc and PCE decreased dramatically after annealing treatment, which was due to the self aggregation of the fullerene derivatives in the as-cast blend films (Fig. 6B and C). As shown in Tables 2 and 3, before the inverted devices were annealed, the changing trend of Voc was as same as that of the LUMO levels, which showed that the Voc was related to the difference between the HOMO level of the p-type polymer and the LUMO level of the $n$ type fullerene derivatives [27-29]. In the cases of OIHC60P
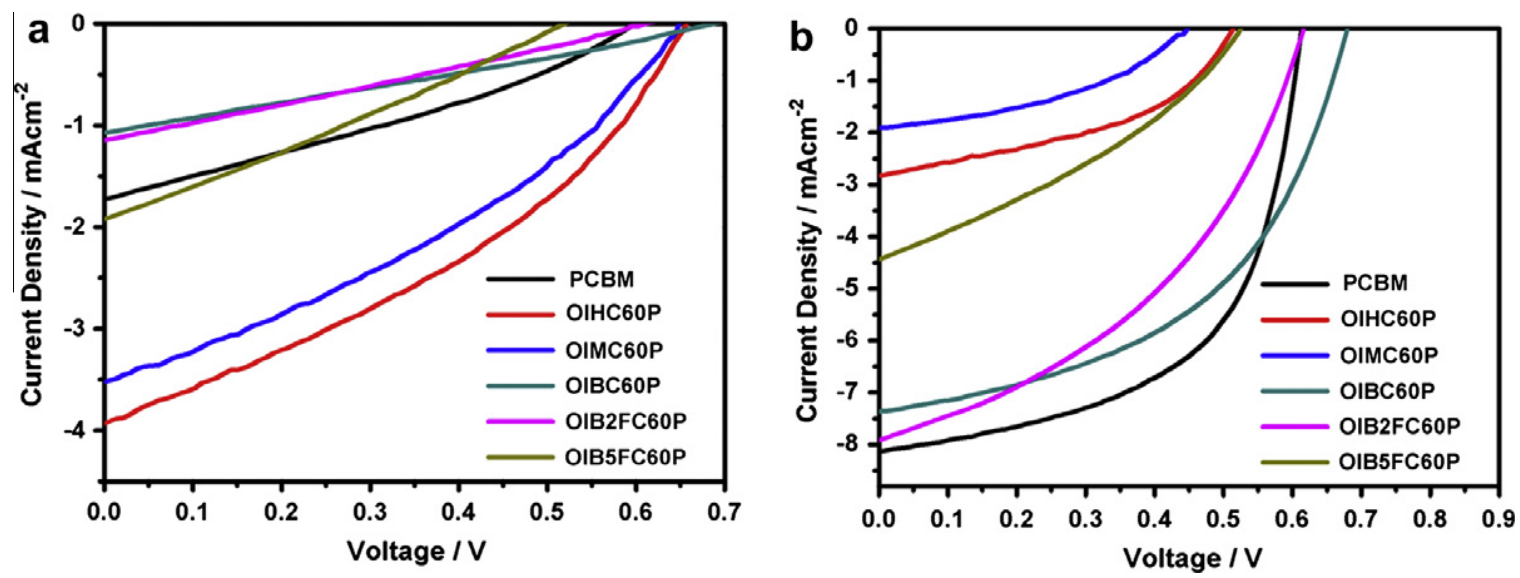

Fig. 7. Current density-voltage curves of inverted-type bulk heterojunction solar cells under simulated $100 \mathrm{~mW} / \mathrm{cm}^{2}(\mathrm{AM} 1.5 \mathrm{G})$ irradiation before (a) and after (b) annealing. 

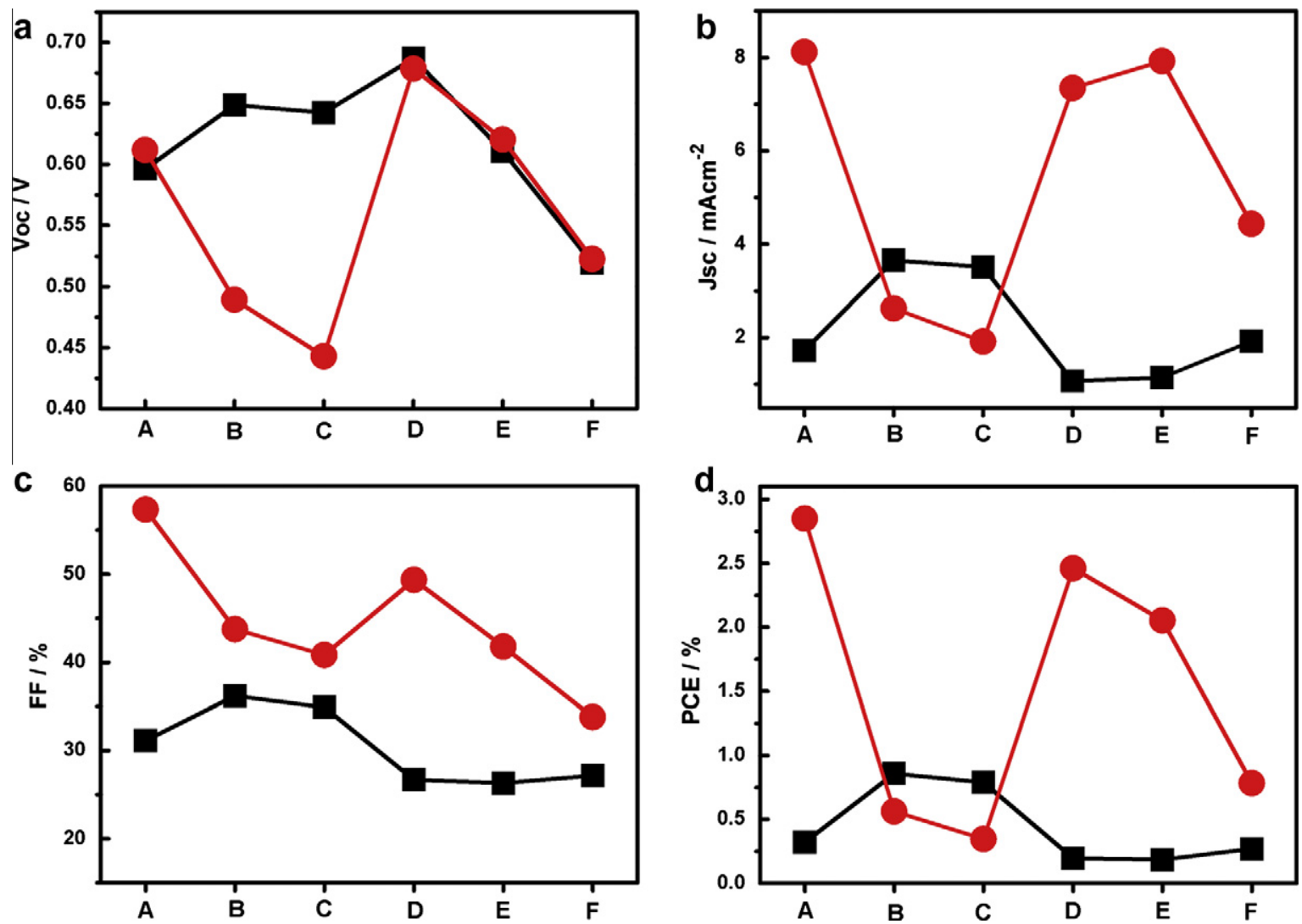

Fig. 8. The open circuit voltage (a), short circuit current (b), fill factor (c), and power conversion efficiency (d) of inverted-type bulk heterojunction photovoltaic devices with P3HT and different fullerene derivatives as active layer. (A-F represents PCBM, OIHC60P, OIMC60P, OIBC60P, OIB2FC60P, and OIB5FC60P, respectively. The black square and red circle represent the films before and after annealing treatment, respectively. (For interpretation of the references to colour in this figure legend, the reader is referred to the web version of this article.)

Table 3

Photovoltaic performance of the P3HT-based devices with different acceptors.

\begin{tabular}{|c|c|c|c|c|c|}
\hline Acceptor & & $\operatorname{Voc}(V)$ & $\mathrm{Jsc}\left(\mathrm{mA} / \mathrm{cm}^{2}\right)$ & $\mathrm{FF}$ & PCE (\%) \\
\hline \multirow[t]{2}{*}{ PCBM } & Before annealing & 0.60 & 1.72 & 0.31 & 0.32 \\
\hline & After annealing & 0.61 & 8.12 & 0.57 & 2.85 \\
\hline \multirow[t]{2}{*}{ ОIHC60P } & Before annealing & 0.65 & 3.66 & 0.36 & 0.86 \\
\hline & After annealing & 0.49 & 2.63 & 0.44 & 0.56 \\
\hline \multirow[t]{2}{*}{ OIMC60P } & Before annealing & 0.64 & 3.52 & 0.35 & 0.79 \\
\hline & After annealing & 0.44 & 1.92 & 0.41 & 0.35 \\
\hline \multirow[t]{2}{*}{ OIBC60P } & Before annealing & 0.69 & 1.07 & 0.27 & 0.20 \\
\hline & After annealing & 0.68 & 7.35 & 0.49 & 2.46 \\
\hline \multirow[t]{2}{*}{ OIB2FC60P } & Before annealing & 0.61 & 1.15 & 0.26 & 0.18 \\
\hline & After annealing & 0.62 & 7.93 & 0.42 & 2.05 \\
\hline \multirow[t]{2}{*}{ OIB5FC60P } & Before annealing & 0.52 & 1.92 & 0.27 & 0.27 \\
\hline & After annealing & 0.52 & 4.45 & 0.34 & 0.78 \\
\hline
\end{tabular}

and OIMC60P, the Voc values decreased after the devices were annealed in air, which was probably because the annealing treatment induced the phase separation increasing (Fig. 6B and C) and resulted in the change of the contact situation between the donors and the acceptors in the de- vices [52,53]. Interestingly, we found that the changing trends of Voc, Jsc, FF, and PCE of the annealed blend films (Fig. 8, red lines) based on P3HT and different fullerene derivatives were consistent well with the $\Delta h$ values' change in XRD experiment (Fig. 3b). It proved that the 
crystallization structure and morphology of the active layer film play essential roles in the performance of the photovoltaic devices.

\section{Conclusion}

In summary, indole-containing fulleropyrrolidine derivatives with different substitute side groups such as methyl, benzyl, 2,5-difluorobenzyl, and 2,3,4,5,6-pentafluorobenzyl were prepared. All the fulleropyrrolidine derivatives showed similar absorption profile and the absorbance was much higher than that of PCBM in the visible region. The change of the substitute groups on the fulleropyrrolidine derivatives had significant influence on the solubility of the acceptors and the miscibility with P3HT, so the absorption spectra, and morphologies of the blend films based on P3HT and different fullerene derivatives were varied, which allows systematic exploring the effect of the acceptor on the performance of the photovoltaic devices. The inverted solar cells were fabricated with a structure of ITO/ZnO/Poly(3-hexylthiophene)(P3HT):fullerene derivatives/MoO3/Ag. The significant difference in the morphology of the annealed active layer based on P3HT and different fullerene derivatives was observed, leading to remarkable changes of their PCE ranging from 0.35 to $2.46 \%$. The fulleropyrrolidine derivatives are promising acceptors for the application of bulk heterojunction organic solar cells. Interestingly, the changing trends of the photovoltaic parameters (Voc, Jsc, FF, and PCE) based on the annealed blend films were good agreement with the $\Delta h$ values' change in XRD experiment. It provided useful insight into the relationship among the chemical structures such as side groups on the fullerene, crystallization, morphology and performance of the photovoltaic devices.

\section{Acknowledgements}

This work was supported by the Ministry of Science and Technology of China (2010DFA52310), National Natural Science Foundation of China (21204097, 51173199, 61107090), Chinese Academy of Sciences ("One Hundred Talented Program", and KGCX2-YW-399+9-2), Department of Science and Technology of Shandong Province (2010GGC10345), Shandong Provincial Natural Science Foundation (ZR2011BZ007), and Qingdao Municipal Science and Technology Program (11-2-4-22-hz).

\section{Appendix A. Supplementary material}

Supplementary data associated with this article can be found, in the online version, at http://dx.doi.org/10.1016/ j.orgel.2012.12.010.

\section{References}

[1] G. Li, R. Zhu, Y. Yang, Nat. Photon. 6 (2012) 153-161.

[2] J.W. Lee, Y.S. Choi, W.H. Jo, Org. Electron. 13 (2012) 3060-3066.

[3] L. Dou, J. You, J. Yang, C.-C. Chen, Y. He, S. Murase, T. Moriarty, K. Emery, G. Li, Y. Yang, Nat. Photon. 6 (2012) 180-185.

[4] Z.C. He, C.M. Zhong, X. Huang, W.Y. Wong, H.B. Wu, L.W. Chen, S.J. Su, Y. Cao, Adv. Mater. 23 (2011) 4636-4643.
[5] Z. He, C. Zhong, S. Su, M. Xu, H. Wu, Y. Cao, Nat. Photon. 6 (2012) 593-597.

[6] W. Cai, X. Gong, Y. Cao, Sol. Energy Mater. Sol. Cells 94 (2010) 114127.

[7] C.H. Duan, F. Huang, Y. Cao, J. Mater. Chem. 22 (2012) 10416-10434.

[8] S. Guenes, H. Neugebauer, N.S. Sariciftci, Chem. Rev. 107 (2007) 1324-1338.

[9] Y.F. Li, Acc. Chem. Res. 45 (2012) 723-733.

[10] Y.Y. Liang, L.P. Yu, Acc. Chem. Res. 43 (2010) 1227-1236.

[11] H.B. Liu, J.L. Xu, Y.J. Li, Y.L. Li, Acc. Chem. Res. 43 (2010) 1496-1508.

[12] P. Dutta, H. Park, W.-H. Lee, I.-N. Kang, S.-H. Lee, Org. Electron. 13 (2012) 3183-3194.

[13] X.J. Wan, Y. Huang, Y.S. Chen, Acc. Chem. Res. 45 (2012) 598-607.

[14] P.M. Beaujuge, J.M.J. Fréchet, J. Am. Chem. Soc. 133 (2011) 2000920029.

[15] Y. He, Y. Li, Phys. Chem. Chem. Phys. 13 (2011) 1970-1983.

[16] C.-Z. Li, H.-L. Yip, A.K.Y. Jen, J. Mater. Chem. 22 (2012) 4161-4177.

[17] W. Kylberg, Y. Zhang, A. Aebersold, F.A. de Castro, T. Geiger, J. Heier, S. Kuster, C.Q. Ma, P. Bauerle, F. Nuesch, J.N. Tisserant, R. Hany, Org. Electron. 13 (2012) 1204-1212.

[18] Y.Y. Liang, Z. Xu, J.B. Xia, S.T. Tsai, Y. Wu, G. Li, C. Ray, L.P. Yu, Adv. Mater. 22 (2010) E135-E138.

[19] A. Loiudice, A. Rizzo, G. Latini, C. Nobile, M. de Giorgi, G. Gigli, Sol. Energy Mater. Sol. Cells 100 (2012) 147-152.

[20] F. Machui, S. Langner, X.D. Zhu, S. Abbott, C.J. Brabec, Sol. Energy Mater. Sol. Cells 100 (2012) 138-146.

[21] A.T. Mallajosyula, S.S.K. Iyer, B. Mazhari, Org. Electron. 13 (2012) 1158-1165.

[22] Y. He, H.-Y. Chen, J. Hou, Y. Li, J. Am. Chem. Soc. 132 (2010) 13771382.

[23] H.U. Kim, D. Mi, J.-H. Kim, J.B. Park, S.C. Yoon, U.C. Yoon, D.-H. Hwang, Sol. Energy Mater. Sol. Cells 105 (2012) 6-14.

[24] J.H. Seo, S.Y. Nam, K.-S. Lee, T.-D. Kim, S. Cho, Org. Electron. 13 (2012) 570-578.

[25] M.I. Valitov, I.P. Romanova, A.A. Gromchenko, G.R. Shaikhutdinova, D.G. Yakhvarov, V.V. Bruevich, V.A. Dyakov, O.G. Sinyashin, D.Y. Paraschuk, Sol. Energy Mater. Sol. Cells 103 (2012) 48-52.

[26] Y.-J. Cheng, M.-H. Liao, C.-Y. Chang, W.-S. Kao, C.-E. Wu, C.-S. Hsu, Chem. Mater. 23 (2011) 4056-4062.

[27] K.-H. Kim, H. Kang, H.J. Kim, P.S. Kim, S.C. Yoon, B.J. Kim, Chem. Mater. 24 (2012) 2373-2381.

[28] K. Matsumoto, K. Hashimoto, M. Kamo, Y. Uetani, S. Hayase, M. Kawatsura, T. Itoh, J. Mater. Chem. 20 (2010) 9226-9230.

[29] B.-Y. Ren, C.-J. Ou, C. Zhang, Y.-Z. Chang, M.-D. Yi, J.-Q. Liu, L.-H. Xie, G.-W. Zhang, X.-Y. Deng, S.-B. Li, W. Wei, W. Huang, J. Phys. Chem. C 116 (2012) 8881-8887.

[30] J.H. Choi, K.I. Son, T. Kim, K. Kim, K. Ohkubo, S. Fukuzumi, J. Mater. Chem. 20 (2010) 475-482.

[31] Y. Zhang, H.L. Yip, O. Acton, S.K. Hau, F. Huang, A.K.Y. Jen, Chem. Mater. 21 (2009) 2598-2600.

[32] A.M. Lopez, A. Mateo-Alonso, M. Prato, J. Mater. Chem. 21 (2011) 1305-1318.

[33] K. Yoshimura, K. Matsumoto, Y. Uetani, S. Sakumichi, S. Hayase, M. Kawatsura, T. Itoh, Tetrahedron 68 (2012) 3605-3610.

[34] T. Itoh, M. Mishiro, K. Matsumoto, S. Hayase, M. Kawatsura, M. Morimoto, Tetrahedron 64 (2008) 1823-1828.

[35] J.K. Lee, K. Fujida, T. Tsutsui, M.R. Kim, Sol. Energy Mater. Sol. Cells 91 (2007) 892-896.

[36] S.E. Walden, R.A. Wheeler, J. Chem, Soc, Perkin Trans. 2 (1996) 26532662.

[37] S.Q. Xiao, Y.L. Li, Y.J. Li, J.P. Zhuang, N. Wang, H.B. Liu, B. Ning, Y. Liu, F.S. Lu, L.Z. Fan, C.H. Yang, Y.F. Li, D.B. Zhu, J. Phys. Chem. B 108 (2004) 16677-16685.

[38] P.A. Troshin, H. Hoppe, J. Renz, M. Egginger, J.Y. Mayorova, A.E. Goryochev, A.S. Peregudov, R.N. Lyubovskaya, G. Gobsch, N.S. Sariciftci, V.F. Razumov, Adv. Funct. Mater. 19 (2009) 779-788.

[39] C. Liu, Y.J. Li, C.H. Li, W.W. Li, C.J. Zhou, H.B. Liu, Z.S. Bo, Y.L. Li, J. Phys. Chem. C 113 (2009) (1975) 21970-21975.

[40] W.H. Baek, T.S. Yoon, H.H. Lee, Y.S. Kim, Org. Electron. 11 (2010) 933-937.

[41] F.C. Chen, C.J. Ko, J.L. Wu, W.C. Chen, Sol. Energy Mater. Sol. Cells 94 (2010) 2426-2430.

[42] H. Cheun, C. Fuentes-Hernandez, Y. Zhou, W.J. Potscavage, S.-J. Kim, J. Shim, A. Dindar, B. Kippelen, J. Phys. Chem. C 114 (2010) 2071320718.

[43] B.S. Rolczynski, J.M. Szarko, H.J. Son, Y. Liang, L. Yu, L.X. Chen, J. Am. Chem. Soc. 134 (2012) 4142-4152.

[44] J.-H. Huang, C.-Y. Yang, C.-Y. Hsu, C.-L. Chen, L.-Y. Lin, R.-R. Wang, K.C. Ho, C.-W. Chu, ACS Appl. Mater. Interfaces 1 (2009) 2821-2828. 
[45] W.H. Baek, H. Yang, T.S. Yoon, C.J. Kang, H.H. Lee, Y.S. Kim, Sol Energy Mater. Sol. Cells 93 (2009) 1263-1267.

[46] J. Liu, R. Zhang, G.v. Sauve, T. Kowalewski, R.D. McCullough, J. Am. Chem. Soc. 130 (2008) 13167-13176.

[47] S. Lilliu, T. Agostinelli, E. Pires, M. Hampton, J. Nelson, J.E. Macdonald, Macromolecules 44 (2011) 2725-2734.

[48] H.J. Son, W. Wang, T. Xu, Y. Liang, Y. Wu, G. Li, L. Yu, J. Am. Chem. Soc. 133 (2011) 1885-1894.

[49] H. Wang, Y. He, Y. Li, Su, J. Phys. Chem. A 116 (2012) 255-262.
[50] C.T. Chapman, W. Liang, X. Li, J. Phys. Chem. Lett. 2 (2011) 11891192.

[51] F. Machui, S. Rathgeber, N. Li, T. Ameri, C.J. Brabec, J. Mater. Chem. 22 (2012) 15570-15577.

[52] A. Pivrikas, P. Stadler, H. Neugebauer, N.S. Sariciftci, Org. Electron. 9 (2008) 775-782.

[53] T.L. Wang, A.C. Yeh, C.H. Yang, Y.T. Shieh, W.J. Chen, T.H. Ho, Sol. Energy Mater. Sol. Cells 95 (2011) 3295-3302. 